\title{
The impact of tourists on Antarctic tardigrades: an ordination-based model
}

\author{
Sandra J. McINNES, ${ }^{1 *}$ Philip J.A. PUGH ${ }^{2}$ \\ ${ }^{1}$ British Antarctic Survey, Natural Environment Research Council, High Cross, Madingley Road, Cambridge, CB3 0ET, UK; \\ ${ }^{2}$ Department of Life Sciences, Anglia Ruskin University, East Road, Cambridge, CB1 1PT, UK \\ *Corresponding author: s.mcinnes@bas.ac.uk
}

\begin{abstract}
Tardigrades are important members of the Antarctic biota yet little is known about their role in the soil fauna or whether they are affected by anthropogenic factors. The German Federal Environment Agency commissioned research to assess the impact of human activities on soil meiofauna at 14 localities along the Antarctic peninsula during the 2009/2010 and 2010/2011 austral summers. We used ordination techniques to re-assess the block-sampling design used to compare areas of high and low human impact, to identify which of the sampled variables were biologically relevant and/or demonstrated an anthropogenic significance. We found the most significant differences between locations, reflecting local habitat and vegetation factor, rather than within-location anthropogenic impact. We noted no evidence of exotic imports but report on new maritime Antarctic sample sites and habitats.
\end{abstract}

Key words: Tardigrada, soil, alien introduction, maritime Antarctic.

\section{INTRODUCTION}

The introduction of exotic taxa is regarded as a major threat to native species even in Antarctica (Chown et al., 2012; Greenslade and Convey, 2012), where the maritime Antarctic peninsula is of particular concern as it is vulnerable to rapid regional climate warming (Meredith and King, 2005; Turner et al., 2005, 2009) and anthropogenic (tourist/scientific) activity (Lamers et al., 2008; Hughes et al., 2010; IAATO, 2012). Climate change and human activity compromise natural dispersal barriers, accelerating the ingress and survival of exotic species (Chown et al., 2012). While the Antarctic tourist industry has introduced boot washing, clothing decontamination and other preventative measures to limit anthropogenic introduction (IAATO, 2010), their efficacy is unknown.

Antarctic tardigrades were first recorded from Continental Gaussberg (Richters, 1904), and the Maritime South Orkney islands (Murray, 1906). The most recent estimate of $c a$. 70 species (Convey and McInnes, 2005; McInnes, personal database) not only continues to climb, but suggests that tardigrades are a major component of the Antarctic micro-fauna (Convey and McInnes, 2005). Minimal predation pressure, perennial food abundance and highly developed cryptobiotic survival strategies have allowed Antarctic species to reach very high population densities of 10 to 1000 times greater than those encountered in temperate or tropical regions (Jennings, 1979; McInnes and Pugh, 1999; McInnes et al., 2001). This apparent and unusual ascendancy, coupled with cryptobiosis and other extremophile survival strategies (Wright, 2001; Rebecchi et al., 2007) make tardigrades ideal candidates for human mediated transportation.
The German Federal Environment Agency commissioned a study into the impact of ship-based tourism on Antarctic terrestrial soil ecosystems, focusing on a range of taxa including Tardigrada. The a-priori objective of this study was to quantify biotic and abiotic differences between designated anthropogenic samples collected on identifiable tourist trails compared with adjacent non-anthropogenic samples. We report on this first study to use tardigrades as models of anthropogenic introduction and/or disturbance to Antarctic edaphic and hemi-edaphic communities.

\section{METHODS}

Soil and vegetation samples were collected on several tourist cruises during the 2010 and 2011 (Jan/Feb) Austral summers. Landings were made at eleven sites along the maritime Antarctic peninsula and islands including Paulet island, Devil island, Neko harbour, and Petermann island, together with several locations in the South Shetland archipelago: Arctowski station, Biologenbucht, Ardley island, and Punta Cristian (King George island), Halfmoon island, Hannah point (Livingston island), together with two adjacent sites (Whaler's bay and Telefon bay) on Deception island (Fig. 1). Three ca. $50 \times 50 \mathrm{~mm}$ bare soil, soil with vegetation and other substrate/microhabitat samples were collected at each site. These samples were designated as being anthropogenic (A) if collected from a clear tourist trail and non-anthropogenic (B) if collected away from such trails. The samples were shipped within 1-2 weeks of sampling, at $1-2 \pm 2^{\circ} \mathrm{C}$, to Germany for treatment including grain size analysis, (Baermann funnel) invertebrate extraction, preservation, sorting (Russell et al., 
2012), and subsequent identification of tardigrades by one of us (SJM).

We compiled three highly compressed MS Excel spreadsheets from the original data of location with (a) binary [presence/absence (1/0)] vegetation taxa, (b) binary verified/putative tardigrade taxa, and (c) numerical abiotic environmental variables. The latter included vegetation index (proportion of vegetation in samples), soil temperature, water content, $\mathrm{pH}$, ignition loss (total oxidation of organic material in a furnace at $500+{ }^{\circ} \mathrm{C}$ ), nitrogen content, carbon content, carbon/nitrogen ratio and particle size in terms of seven $(<0.063,0.063<0.2,0.2<0.63,0.63<2.0$, $2.0<6.3,6.3<20$ and $20+\mathrm{mm} \varnothing$ ) size classes. We condensed the raw data in MS Excel; first removing blank lines, then merging replicate sample lines to (vegetation and tardigrade taxa) net presence/absence, or (environmental variables) means. This yielded three condensed: vegetation (30 row $\times 46$ column), tardigrade $30 \times 18$ and environmental $(26 \times 15)$, matrices suitable for ordination analysis.

We exported the three matrices to the Multivariate Statistics Package (MVSP version 3.13 - Kovach, 2004) where we applied principal components analysis (PCA Pearson, 1901). We presented the environmental data both as is and with a selective, excluding $\mathrm{pH}$ and categorical vegetation index, $\log _{\mathrm{e}}$ (Palmer, 2006) transformation. We performed PCA on covariance matrices of binary vegetation and tardigrade data but on a correlation matrix of the variable-scale abiotic variables (Jolliffe, 2002). We output the results as centred scatter plots of (location) case scores with overlying environmental/plant/tardigrade vectors, along with variance extracted by axes constrained under Kaiser's Rule (Legrende and Legrende, 1983).

The data contained a number of partially identified plant and tardigrade taxa yielding a number of spurious site endemic signals which we deleted or, where possible, collapsed to more robust congeners. This reduced vegetation from 46 to 30 taxa and tardigrades from 18 to 15 . The environmental variables also contained a large proportion of redundant data. We deleted the stochastic/single event temperature and water content leaving two interdependent variable sets: i) ignition loss, carbon content, nitrogen content, and carbon/nitrogen

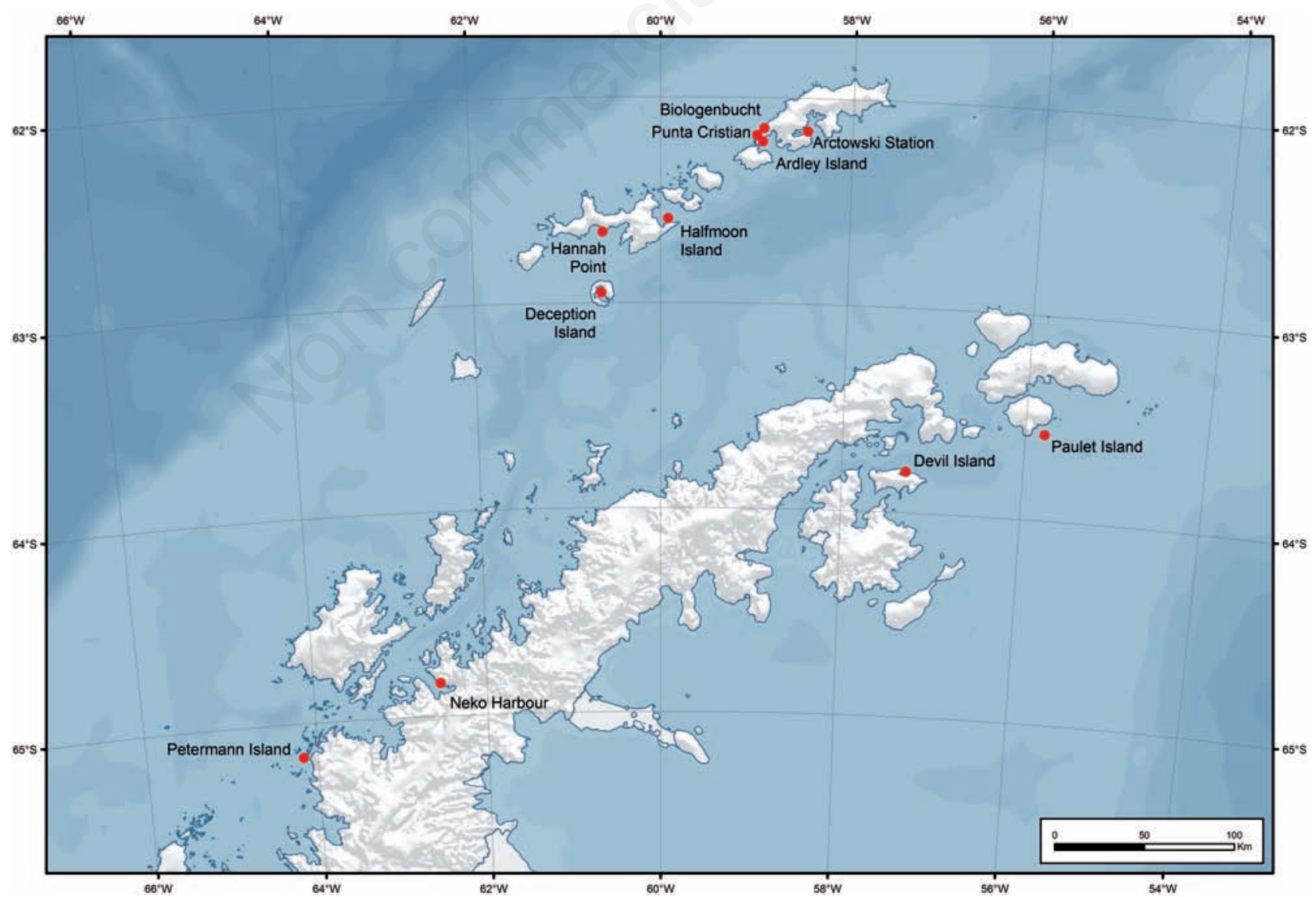

Fig. 1. Map of Antarctic peninsula showing sample sites from cruise ships routes and near scientific research stations during the Austral summers (January/February) 2010 and 2011. 
ratio; together with ii) the seven particle size classes, which violate the principal of variable independences fundamental to ordination (Jolliffe, 2002). This was confirmed by initial PCA where set $A$ vectors were significant, equitable and, near parallel to (correlated with) axis 1 , so we retained the maximal (extractable variance) signal of ignition loss as a soil organic content proxy. Similarly, set B particle sizes formed three discrete fine $(<0.63 \mathrm{~mm})$, medium $(0.63<6.3 \mathrm{~mm})$ and coarse $(6.3<\mathrm{mm})$, vector groups separated by $>90^{\circ}$ about the centred scatterplot origin. We redefined particle size in terms of these three classes in subsequent analyses.

We combined all three data sets using canonical correspondence analysis (CCA) (Ter Braak, 1986), to maximise correspondence/inertia between the 26 locations, 30 plant and 14 tardigrade taxa with six overlying environmental variable Euclidean stress vectors (Ter Braak and Šmilauer, 1998). The output biplot proved very cluttered so we reduced the plants to four congruent (alga, flowering plant, lichen and moss) categories. We ran the environmental variables both as is and (excluding $\mathrm{pH} /$ vegetation index) $\log _{\mathrm{e}}$ transformed (Palmer, 2006); though both runs proved similar in terms of axis 1 and 2 non-constrained (23.2 vs 24.7\%) and constrained ( $70.8 v s$ $63.8 \%$ ) combined variance extraction. The collinear/redundant (sensu Shaw, 2003) fine sediment fraction vector is omitted along with Telefon bay B, which had neither vegetation nor tardigrade.

\section{RESULTS}

Only three of the eleven sites were sampled in both 2010 and 2011. The 328 samples collected from both years yielded 17 tardigrade taxa (Tab. 1), representing two classes and five families. Two of these taxa, Diphascon (Adropion) sp. and Isohypsibius sp., are new to science and will be described elsewhere.

There are four environmental location groups (Fig. 2). (Group 2a) High pH - Neko Hb. A and B (i.e. $\mathrm{A}=$ anthropogenic and $\mathrm{B}=$ non-anthropogenic), Petermann $\mathrm{A}$ and $\mathrm{B}$. (Group 2b) Fine $(<0.63 \mathrm{~mm})$ sediment - Biologenbucht A and B, Deception B, Hannah Pt A and B and Pt. Cristian $1 \mathrm{~A}$ and $\mathrm{B}$. The juxtaposition of the vegetation index vector with group $2 \mathrm{~b}$ is an artefact; it really implies that groups $2 \mathrm{a}$ and $2 \mathrm{c}$ (above axis 1) include samples which contained no vegetation. (Group 2c) Medium $(0.63<6.3$

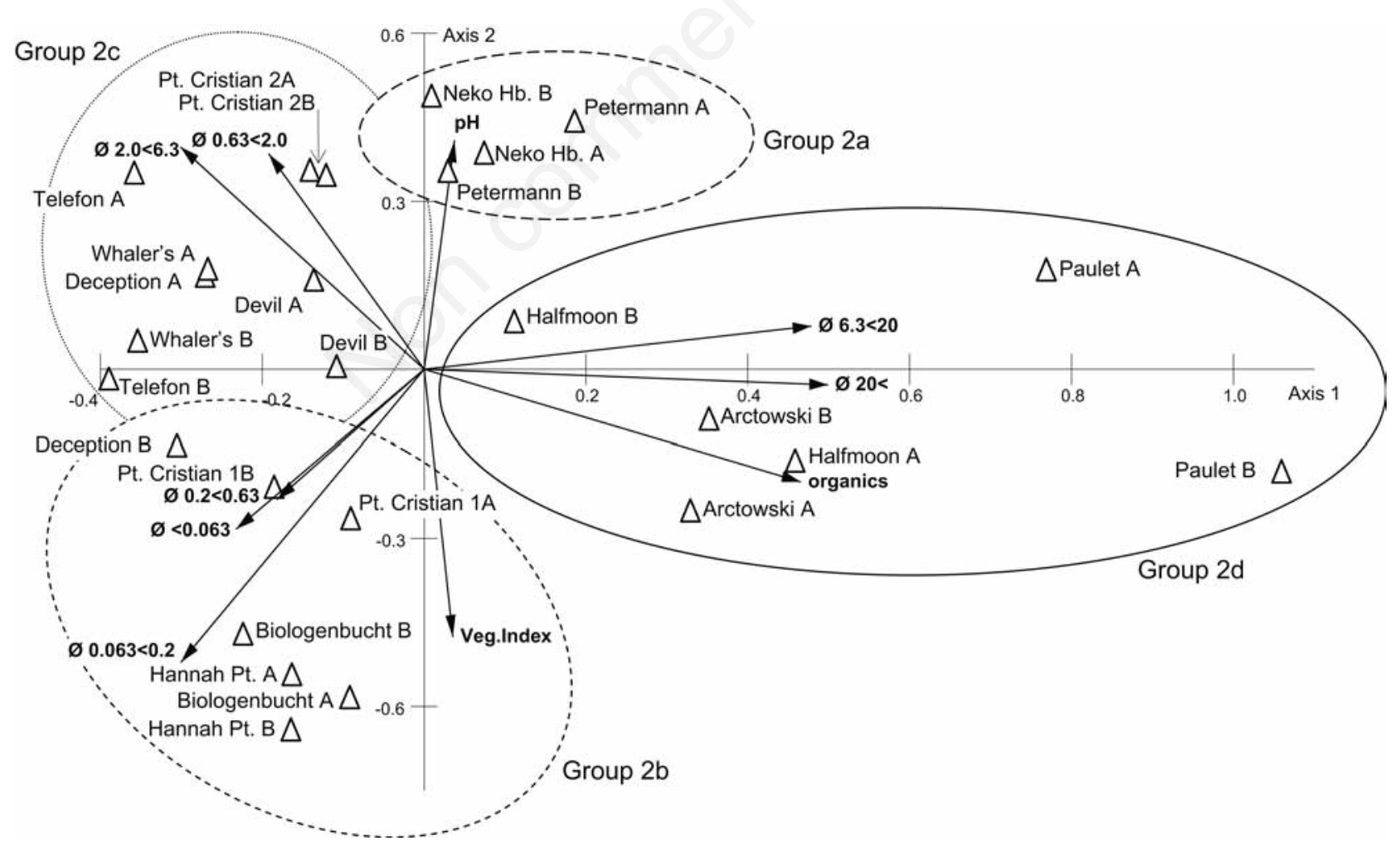

Fig. 2. Abiotics. Principal components analysis correlation matrix biplot showing binary locations $(\Delta)$ and abiotic factors as Euclidean stress vectors $(\rightarrow)$; some $54.55 \%$ of total variance extracted by axes $1(30.6 \%)$ and $2(23.9 \%)$. Heavy dashed oval, Group $2 \mathrm{a}$; light dashed oval, Group 2b; dotted oval, Group 2c; solid oval, Group 2d. 


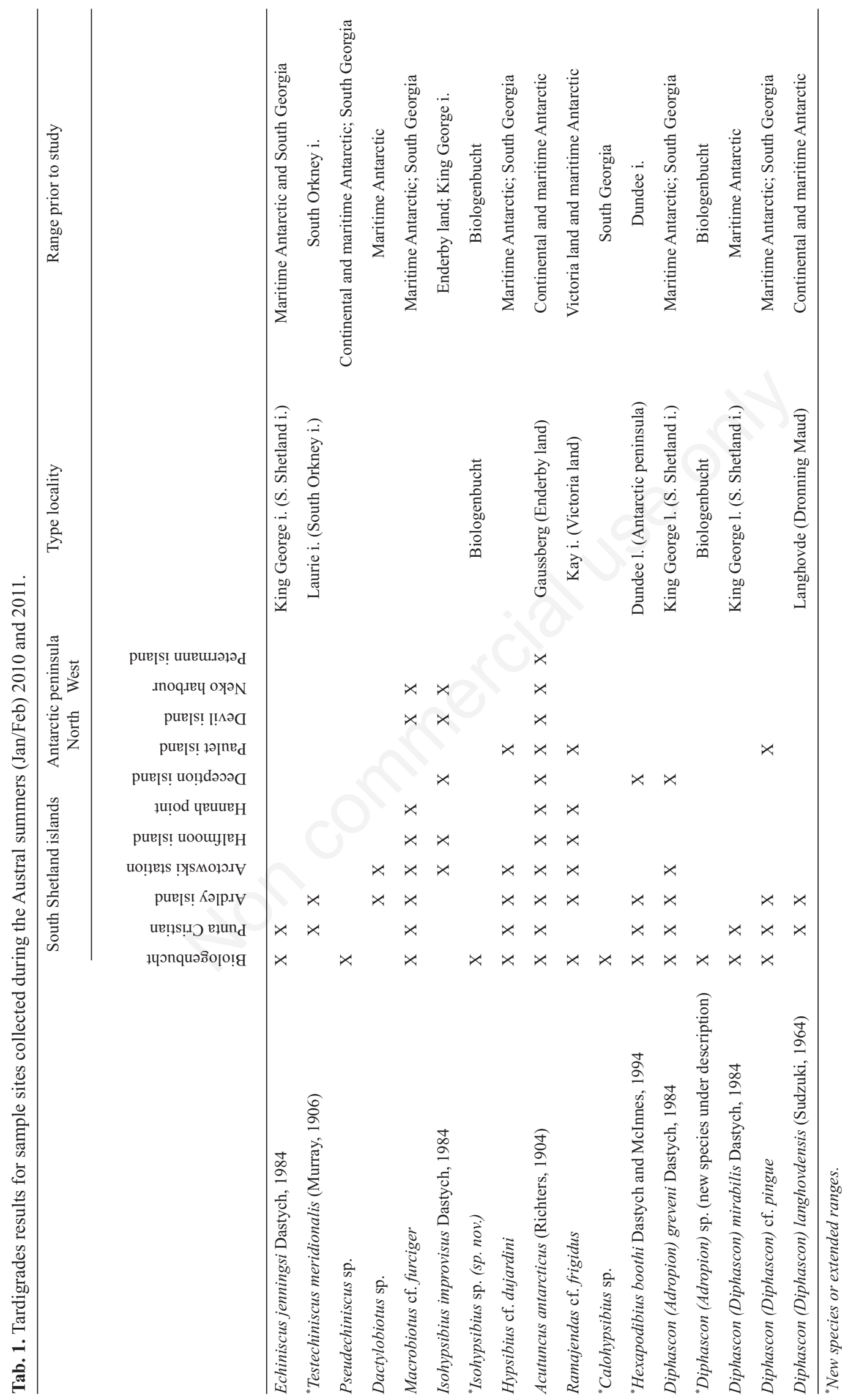


mm) sediment with no vegetation - Deception A, Devil A and B, Pt. Cristian $2 \mathrm{~A}$ and B, Telefon A and B, Whaler's $A$ and B. (Group 2d) Coarse $(6.3<\mathrm{mm})$ sediment with a high organic content - Arctowski A and B, Halfmoon A and B and Paulet A and B.

Fig. 3 presented four principal vegetation location groups. (Group 3a) Pt. Cristian $1 \mathrm{~A}$ and B with 8 lichens and 6 mosses. (Group 3b) Ardley A and B, Biologenbucht A and B, Pt. Cristian $2 \mathrm{~A}$ and $\mathrm{B}$ - algae, 4 lichens and 4 mosses. (Group 3c) Deception B, Hannah Pt. A and B and Paulet B - Prasiola (alga) and Ceratodon (moss). (Group 3d) Arctowski A and B - Prasiola and two flowering plants. No vegetation was collected from Deception A, Devil A and B, Halfmoon A and B, Neko Hb. A and B, Paulet A, Petermann A and B, Pt. Telefon A and B or Whaler's A and B.

The tardigrades form four principal location groups (Fig. 4). (Group 4a) Devil A and B, Hannah Pt. A and B, Halfmoon A and B, Neko Hb. A and B, Paulet B, Petermann A and B, Whaler's A and B - all sharing combinations of Acutuncus antarcticus (Richters, 1904), Macrobiotus cf. furciger and Ramajendas cf. frigida. This grouping, clearly evident in that the data is only displayed by the points being parallel to the three tardigrade vectors. (Group 4b) Arctowski B, Ardley A and B - as Group 4a but with the addition of Dactylobiotus sp. (Group 4c) Biologenbucht A and B, Pt. Cristian 1A and B, 2A and B and Paulet A - Calohypsibius sp., Diphascon (Adropion) sp., Diphascon (Diphascon) sp., Echiniscus jenningsi Dastych, 1984, Testechiniscus meridionalis (Murray, 1906), Hexapodibius sp., Hypsibius cf. dujardini, Isohypsibius new sp., Pseudechiniscus sp. (Group 4d) Arctowski A, Deception A and B, Telefon A - show no discernible pattern. No tardigrades were recovered from Telefon B (Group 4e).

Canonical correspondence analysis (Fig. 5) identifies four principal abiotic/location/plant and tardigrade groupings. (Group 5a) Medium sediment, high pH: Biologenbucht A and B, Deception B, Pt. Cristian 1A and B, 2A and $\mathrm{B}$ and Telefon A - lichens and mosses, E. jenningsi, T. meridionalis, Pseudechiniscus sp., Isohypsibius new sp., Calohypsibius sp. and Hexapodibius sp. (Group 5b) Coarse sediment, algae - Arctowski B, Hannah Pt. A and $\mathrm{B}$ and Paulet A and B - Group 5a tardigrades together with Diphascon (Adropion) sp. and Diphascon (Diphascon) sp. (Group 5c) Arctowski A, Deception A, Devil A and B, Halfmoon A and B, Neko Hb. A and B, Petermann A and B, Whaler's A and B - flowering plants, Group 5b tardigrades together with Dactylobiotus sp. and Isohypsibius

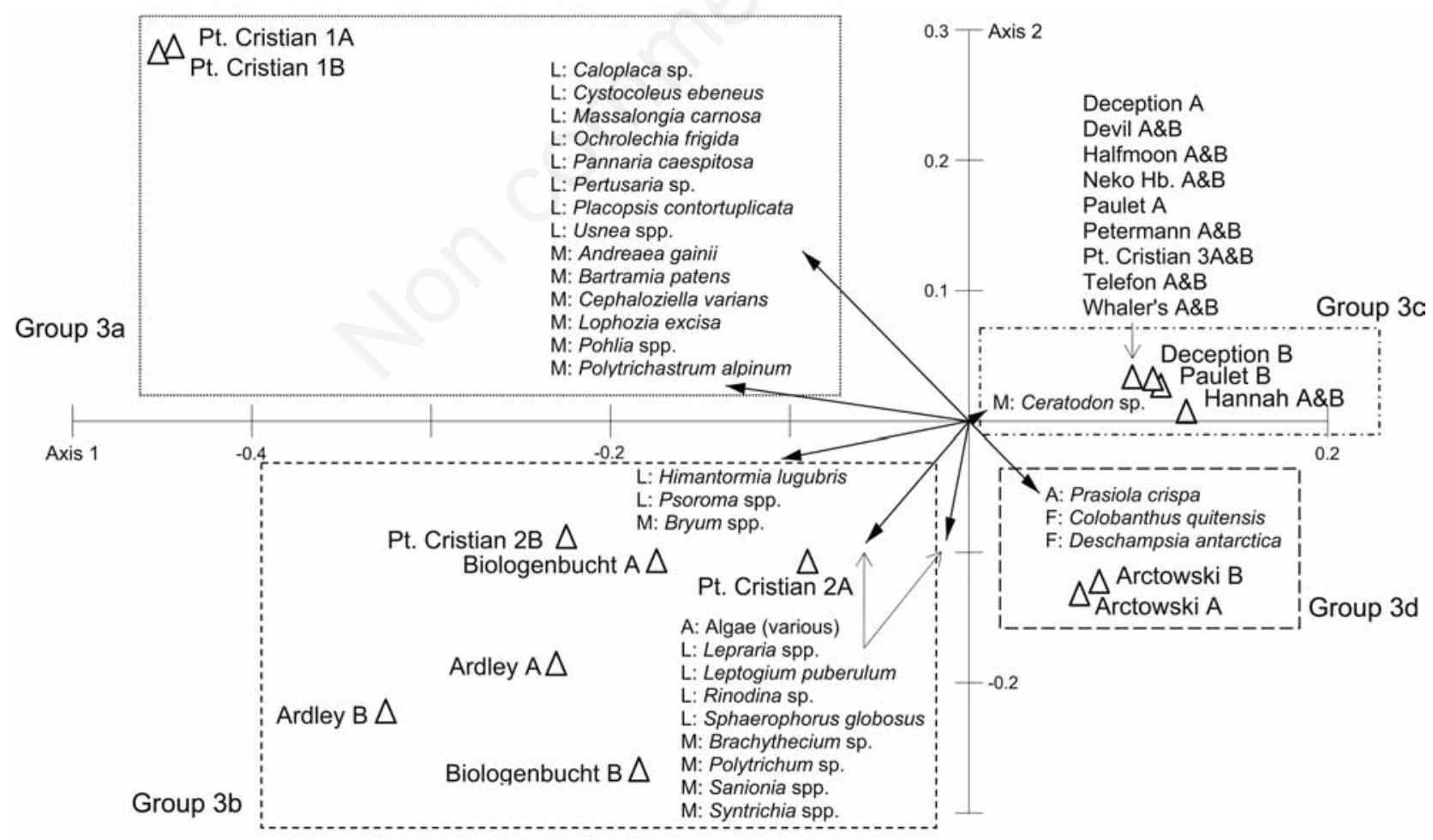

Fig. 3. Plants. Principal components analysis covariance matrix biplot showing binary vegetation locations $(\Delta)$ and abiotic factors as Euclidean stress vectors $(\rightarrow)$; with $44.5 \%$ of total variance extracted by axes 1 (26.7\%) and 2 (17.7\%). Dotted box, Group 3a; light dashed box, Group 3b; dotted and dashed box, Group 3c; Group 3d, heavy dashed box. 
improvisus (Group 5d) Tardigrades common to all sites A. antarcticus, Hypsibius cf. dujardini, Macrobiotus $\mathrm{cf}$. furciger and Ramajendas cf. frigida.

\section{DISCUSSION}

In addition to two new species, this study has extended the range of three taxa: T. meridionalis and Calohypsibius sp. (southward) and Hexapodibius boothi Dastych and McInnes, 1994 (northward) (Tab. 1).

Our analysis only yielded useful signals because we compressed the data and removed multiple redundant environmental variables. Single temperature records, for example, yielded no useful indication of annual variation while water content reflects the current weather or seasonal, e.g. spring snow-melt, conditions and has the potential to interact with soil particle size. PCA extracted more useful signals if these data were omitted and vegetation reduced to a single index.

The data show overriding site fidelity (Pita et al., 2010; Buchanan et al., 2012) with no indication of an anthropogenic (A) vs non-anthropogenic (B) division. CCA (Fig. 5) does however imply that tardigrades are influenced by vegetation and habitat correlating with, for ex- ample, small to medium particle soils, which provide stable rooting media for higher plants, rather than larger, more mobile pebbles and stones (Denef and Six 2005; Barni et al., 2007; Asaeda et al., 2011). There is however little evidence of any other larger-scale congruent patterns with, for example, only Pt. Cristian and Biologenbucht (all four analyses) or Neko harbour and Petermann i. (abiotics, tardigrades, 3-way analysis) grouping together between analyses. This could reflect either an absence of such signals per se or equally an absence of such signals in these highly modified and collapsed data.

There is indisputable evidence for human mediated transport of terrestrial meiofauna that is increasingly being documented (Wilkinson, 2010; Perrigo et al., 2012). Within the Antarctic, accidental importation of soils attached to machinery has also been reported (Hughes et $a l ., 2010)$ prompting assessment of the current management protocols for dealing with non-native introductions (Hughes and Convey, 2012). The original remit of this study was to explore the potential signal of tourist mediated anthropogenic influence on soil organism, including tardigrades, in the maritime Antarctic. Our results show the direct human effect on the tardigrades is less signifi-

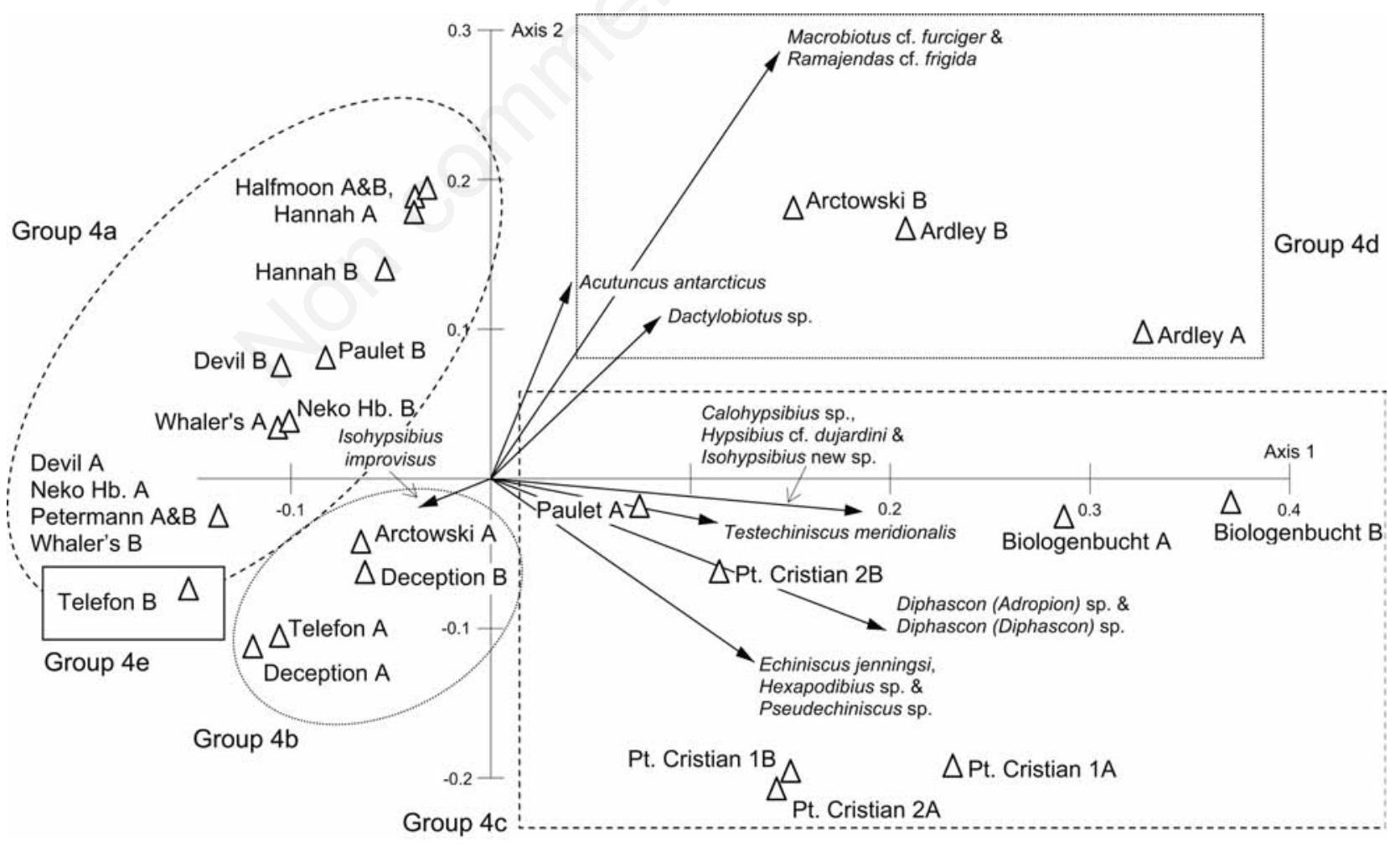

Fig. 4. Tardigrades. Principal components analysis covariance matrix biplot showing binary tardigrade taxa $(\Delta)$ and abiotic factors as Euclidean stress vectors $(\rightarrow)$; with $52.3 \%$ of total variance extracted by axes $1(34.6 \%)$ and 2 (17.7\%). Dashed oval, Group 4a; dotted oval, Group 4b; dashed box, Group 4c; dotted box, Group 4d; solid box, Group 4e. 


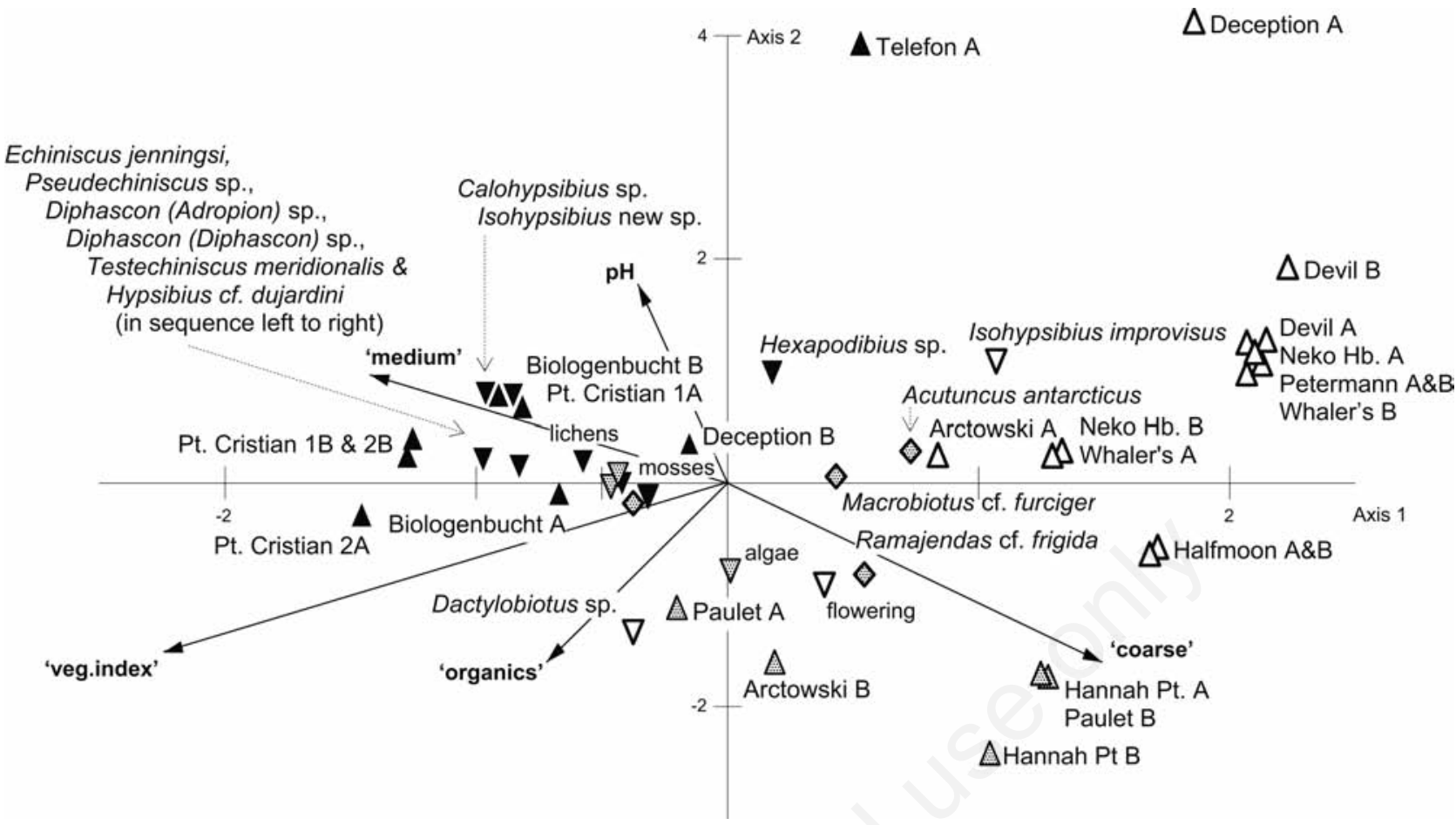

Fig. 5. Plants and Tardigrades vs Environmental. Canonical correspondence analysis triplot showing binary locations ( $\mathbf{\Delta})$, binary vegetation/taxa ( $\boldsymbol{\nabla}$ and $\downarrow)$ and abiotic factors as Euclidean stress vectors $(\rightarrow)$; some $23.8 \%$ of total variance extracted by axes $1(13.6 \%)$ and $2(10.2 \%)$. Black triangles, Group 5a; stippled triangles, Group 5b; white triangles, Group 5c; stippled diamonds, Group 5d.

cant than natural soil and vegetation parameters. The original tenet of anthropogenic $v s$ non-anthropogenic is not supported. The data do however provide both new information on the diversity and range of tardigrades in maritime Antarctic soils and a baseline for further study.

\section{ACKNOWLEDGMENTS}

SJM is grateful to David Russell and Karin Hohberg (Senckenberg Museum of Natural History, Görlitz, Germany) for recruitment to identify tardigrades for the UBA F\&E Project FKZ 370985157.

\section{REFERENCES}

Asaeda T, Rashid MH, Kotagiri S, Uchida T, 2011. The role of soil characteristics in the succession of two herbaceous lianas in a modified river floodplain. River Res. Appl. 27:591-601.

Barni E, Freppaz M, Siniscalco C, 2007. Interactions between vegetation, roots, and soil stability in restored high-altitude ski runs in the Alps. Arctic Antarct. Alpine Res. 39:25-33.

Buchanan JB, Lyons JE, Salzer LJ, Carmona R, Arce N, Wiles GJ, Brady K, Hayes GE, Desimone SM, Schirato G, Michaelis W, 2012. Among-year site fidelity of red knots during migration in Washington. J. Field Ornithol. 83:282289.
Chown SL, Huiskes AHL, Gremmen NJM, Lee JE, Terauds A, Crosbie K, Frenot Y, Hughes KA, Imura S, Kiefer K, Lebouvier M, Raymond B, Tsujimoto M, Ware C, Van de Vijver B, Bergstrom DM, 2012. Continent-wide risk assessment for the establishment of non indigenous species in Antarctica. PNAS 2012 109:4938-4943.

Convey P., McInnes SJ, 2005. Exceptional, tardigrade dominated ecosystems in Ellsworth Land, Antarctica. Ecology 86:519-527.

Denef K, Six, J,2005. Clay mineralogy determines the importance of biological versus abiotic processes for macroaggregate formation and stabilization. Eur. J. Soil Sci. 56:469-479.

Greenslade P, Convey P, 2012. Exotic Collembola on subantarctic islands: pathways, origins and biology. Biol. Invasions 14:405-417.

Hughes KA, Convey P, 2012. Determining the native/non-native status of newly discovered terrestrial and freshwater species in Antarctica - Current knowledge, methodology and management action. J. Environ. Manag. 93:52-66.

Hughes KA, Convey P, Maslen NR, Smith RIL, 2010. Accidental transfer of non-native soil organisms into Antarctica on construction vehicles. Biol. Invasions 12:875-891.

IAATO, 2010. Boot, clothing and equipment decontamination guidelines for small boat operations. Available from: http://www.jstoriaato.org/stable/30063207docs/Boot_Washing07.pdf 
IAATO, 2012. Antarctic Tourism Fact Sheet 2012-13. International Association of Antarctica Tour Operators ed., Rhode Island: 4 pp.

Jennings PG, 1979. Signy Island reference sites: X. Population dynamics of Tardigrada and Rotifera. B.A.S. Bull. 47:89105.

Jolliffe IT, 2002. Principal components analysis (second edition). Springer, New York: 487 pp.

Kovach WL, 2004. MVSP - A Multi-Variate Statistical Package for Windows, ver. 3.13. Kovach Computing Services, Pentraeth, Wales, UK.

Lamers M, Haase D, Amelung B, 2008. Facing the elements: analysing trends in Antarctic tourism. Tourism Rev. 63:1527.

Legrende L, Legrende P, 1983. Numerical Ecology. Elsevier Scientific Publishing Co., New York: 372 pp.

McInnes SJ, Chown SL, Dartnall HJG, Pugh PJA, 2001 Milnesium tardigradum (Milnesiidae, Apochela, Tardigrada): a monitor of high altitude meiofauna on sub-Antarctic Marion Island. Zool. Anz. 240:461-465.

McInnes SJ, Pugh PJA, 1999. Zonation in Antarctic lakedwelling benthic meiofauna, with emphasis on the Tardigrada. Zool. Anz. 238:283-288.

Meredith MP, King JC, 2005. Rapid climate change in the ocean west of the Antarctic Peninsula during the second half of the 20th century. Geophys. Res. Lett. 32:L19604.

Murray J, 1906. Scottish National Antarctic Expedition: Tardigrada of the South Orkneys. Trans. Roy. Soc. Edinb. 45:323-338.

Palmer MW, 2006. Ordination methods for ecologists. Available from: http://ordination.okstate.edu/overview.htm

Pearson K, 1901. On lines and planes of closest fit to systems of points in space. Philos. Mag. 2:559-572.

Perrigo AL, Romeralo M; Baldauf SL, 2012. What's on your boots: an investigation into the role we play in protist dispersal. J. Biogeogr. 39:998-1003.

Pita R, Mira A, Beja P, 2010. Spatial segregation of two vole species (Arvicola sapidus and Microtus cabrerae) within habitat patches in a highly fragmented farmland landscape. Eur. J. Wildlife Res. 56:651-662.

Rebecchi L, Altiero T, Guidetti R, 2007. Anhydrobiosis: the extreme limit of desiccation tolerance. Invertebr. Surv. J. 4:65-81.

Richters F, 1904. [Vorläufiger Bericht über die antarktische Moosfauna]. [Article in German]. Verh. Dtsch. Zool. Ges. 24:236-239.

Russel D, Hohberg K, Hertel F, Otte V, Christian A, Bruckner A, Potapov M, McInnes SJ, 2012. The role of human activity in the introduction of non-native soil species and in the distribution of soil organisms within the Antarctic Peninsula. In: Proc. XXXII SCAR and Open Science Conference, Antarctic Conservation Challenges in a Century of Changes.

Shaw PJA, 2003. Multivariate statistics for the environmental sciences. Arnold, London: 233 pp.

Ter Braak CJF, 1986. Canonical correspondence analysis: new eigenvector technique for multivariate direct gradient analysis. Ecology 67:1167-1179.

Ter Braak CJF, Šmilauer P, 1998. CANOCO reference manual and user's guide to Canoco for Windows: software for canonical community ordination (version 4). Microcomputer Power, Ithaca: $352 \mathrm{pp}$.

Turner J, Bindschadler RA, Convey P, Di Prisco G, Fahrbach E, Gutt J, Hodgson DA, Mayewski PA, Summerhayes CP, 2009. Antarctic climate change and the environment. SCAR, Cambridge: $526 \mathrm{pp}$.

Turner J, Colwell SR, Marshall GJ, Lachlan-Cope TA, Carleton AM, Jones PD, Lagun V, Reid PA, Iagovkina S, 2005. Antarctic climate change during the last 50 years. Int. J. Climatol. 25:279-294.

Wilkinson DM, 2010. Have we underestimated the importance of humans in the biogeography of free-living terrestrial microorganisms? J. Biogeogr. 37:393-397.

Wright JC, 2001. Cryptobiosis 300 years on from van Leuwenhoek: what have we learned about tardigrades? Zool. Anz. 240:563-582. 